\title{
Culturable cyanobacteria from some selected water bodies located in the major climatic zones of Sri Lanka
}

\author{
Md. Fuad Hossain ${ }^{1,2}$, R.R. Ratnayake, ${ }^{2, *}$, S.A. Kulasooriya ${ }^{2}$, K.L. Wasantha Kumara ${ }^{1}$ \\ ${ }^{1}$ Department of Agricultural Biology, Faculty of Agriculture, University of Ruhuna, Sri Lanka \\ ${ }^{2}$ National Institute of Fundamental Studies, Kandy, Sri Lanka.
}

\begin{abstract}
Cyanobacteria are oxygenic photosynthetic prokaryotes with a wide morphological diversity with some members capable of fixing atmospheric $\mathrm{N}_{2}$. This paper reports on the taxa isolated and cultured from water in selected reservoirs in the Dry, Intermediate and Wet zones of Sri Lanka with the potential of utilizing them for biofuel and other industries including cosmetics. Water samples were concentrated by filtering through plankton net and resuspended in $50 \mathrm{~mL}$ of either in respective reservoir water samples or in distilled water. Aliquots of these were cultured in blue green 11 (BG 11) and GO (same as BG11 media but N-free) media. Cultures were maintained under 2,000 lux light intensity with shaking at $200 \mathrm{rpm}$. A total of 64 cyanobacterial cultures, isolated by repeated sub-culturing in liquid and agar media, were observed under a light microscope for identification. While 16 different taxa were isolated from the Dry Zone, 12 and 5 taxa were isolated from the Wet and Intermediate zones, respectively. The frequency of isolating Oscillatoria sp. was high (10 reservoirs) followed by Microcoleus sp. and Microcystis sp. (each from 6 reservoirs). A strong positive correlation was recorded between cyanobacterial occurrences with abiotic properties such as water temperature, $\mathrm{pH}$ and secchi depth (turbidity). Samples prepared in water from respective reservoirs gave faster growth during culturing than those prepared in distilled water. The occurrence, availability and culturability of the isolates obtained in the present study will be useful in the development of value-added cyanobacterial products and cyanobacteria-based industries including biofuel.
\end{abstract}

Keywords: culturable cyanobacteria, fresh water reservoirs, growth conditions, climatic zones of Sri Lanka.

\section{INTRODUCTION}

Cyanobacteria (blue-green algae) constitute a morphologically diverse and widely distributed group of gram-negative photosynthetic prokaryotes (Pandey, 2015). They are unique among the prokaryotes in possessing the capacity of oxygenic photosynthesis. In addition, the ability of some of these organisms to fix $\mathrm{N}_{2}$ either independently or in symbiosis with other organisms not only contributes to natural ecosystems but is used in certain countries as a biofertilizer in rice cultivation (Kulasooriya, 2012). These qualities make cyanobacteria one of the most successful and widespread group among the prokaryotes, occupying a wide range of terrestrial and aquatic environments (Shatheesh, 2013). Cyanobacteria are also characterized with their high morphological diversity not seen among other prokaryotes. This extends from unicellular to filamentous species with a cell volume ranged over more than five orders of magnitude (Whitton, 2000). Their ability to grow in highly polluted environments is also used in treating sewage and industrial effluents (Cepoi $e t$ al., 2016; Kulasooriya, 2012). Cyanobacteria with an array of light harvesting pigments and superior photosynthetic capabilities are currently looked at as highly attractive candidates for biofuel production, food, feed stocks and high value bioactive compounds (Pereira et al., 2011). The scarcity of information about cyanobacteria reflects the difficulty in purifying and culturing of these microorganisms (Waterbury, 2006). Photosynthetic cyanobacteria have drawn significant attention as they can serve as important sources for cosmetic, food and pharmaceutical products, industrial materials and even in biofuel production.

In Sri Lanka, some studies have been carried out to examine different aspects of cyanobacteria. Jayatissa et al.(2006) investigated the variations in phytoplankton communities in relation to major nutrients, with a particular emphasis on cyanobacteria, sampled from 17 reservoirs from different user categories and climatic zones of Sri Lanka. Another study reported on the occurrence of cyanobacteria in 21 
reservoirs of the Mahaweli river basin in Sri Lanka (Silva and Wijeyaratne, 1999). Perera \& Yatigammana (2014) studied the distribution and composition of cyanobacteria in several Sri Lankan reservoirs. Several studies reported so far on cyanobacteria are from fresh water bodies in Sri Lanka with a special emphasis on toxigenic and bloom forming types of cyanobacteria (Idroos and Manage, 2015; Perera et al., 2012; Magana-Arachchi and Wanigatunge, 2013; Magana-Arachchi et al., 2011; Magana-Arachchi et al., 2009; Pathiratne and Saram, 2010; Jayawardene et al.,1998; Kulasooriya, 1998; Weerakone et al., 1998). Tobschall and Dissanayake (1986) studied heavy metal concentrations in cyanobacterial mats in Mannar lagoon. Hossain et al., (2016) reported on the antioxidant properties of some selected cyanobacterial species of fresh water bodies in Sri Lanka. Several other studies have been carried out since early $20^{\text {th }}$ century on the occurrence of cyanobacteria in Sri Lanka (Abeywickrama, 1979; Crow, 1923; Silva, 1992; Foged and Botanist, 1976; Kulasooriya and Silva, 1981; Holsinger, 1955; Rott and Lenzenweger, 1994; West and West, 1902). The present study reports on the isolation, culturing and identification of cyanobacteria from some selected fresh water reservoirs located in three major climatic zones of Sri Lanka, with the aim of identifying suitable taxa for bio-fuel production and other industries.

\section{MATERIALS AND METHODS}

\section{Sampling}

Thirty seven fresh water reservoirs were selected for the study (Figure 1). Also the GPS coordinates are provided in the appendix. Water samples were collected from 31 reservoirs in the Dry zone and from 3 reservoirs each from Wet and Intermediate zones. From ancient times, many man-made reservoirs are mainly found in the Dry Zone while a lesser number found in the Wet and Intermediate Zones. GPS locations of the sampling reservoirs were recorded using GPS meter (Garmin, eTrex 30).

\section{Collection of water samples}

Water samples were collected using a Ruttner sampler from the photic zone of the reservoir and stored in plastic cans (less than two hours) till the samples were prepared for culturing. The photic zone (turbidity or secchi depth) of the water body was determined by the Secchi disk disappearance technique. At each reservoir, three $2 \mathrm{~L}$ samples were collected (two samples from a distance of 3 to $4 \mathrm{~m}$ from the edge and one from the middle of the water body). Physical parameters of water bodies such as $\mathrm{pH}$ and temperature of water was measured using Hanna pocket $\mathrm{pH}$ and temperature meter (model HI 98128) during sample collection.

\section{Sample preparation}

Each water sample (2 L) was filtered through 20 $\mu \mathrm{m}$ mesh size planktonic net. The material retained in the mesh was transferred into a screw cap plastic tube before making the final volume into $25 \mathrm{~mL}$ by adding distilled water. Another sample was prepared in the same manner but using water from the respective reservoir instead of distilled water. Thus, six separate sub-samples were prepared from each reservoir.

\section{Culturing and sub culturing}

Ten $\mathrm{ml}$ of the planktonic sample was transferred into $50 \mathrm{~mL}$ of BG11 (Stanier et al., 1971) and GO (Rippka et al.,1979; 1981) media at pH 7.5 in $100 \mathrm{~mL}$ conical flasks and maintained with continuous shaking at $200 \mathrm{rpm}$ in a biological growth chamber under 2,000 lux light intensity. Growth was detected in each medium by the appearance of the bluish green color. Once the growth was detected, $100 \mu \mathrm{l}$ of a sub-sample was transferred on to an agar plate (same media solidified with $1.5 \%(\mathrm{w} / \mathrm{v})$ bacteriological agar) using spread plate method under a laminar air flow cabinet (Pulz and Gross, 2004). All the samples were cultured in BG11 and GO media and the number of days to produce visible growth in each medium was observed.

Subcultures were carried out by inoculating $100 \mu \mathrm{l}$ of the vortexed sample on to a petri plate. The purity of the culture was confirmed by repeated plating and regular observations under the microscope (AbouShanab et al., 2011). 


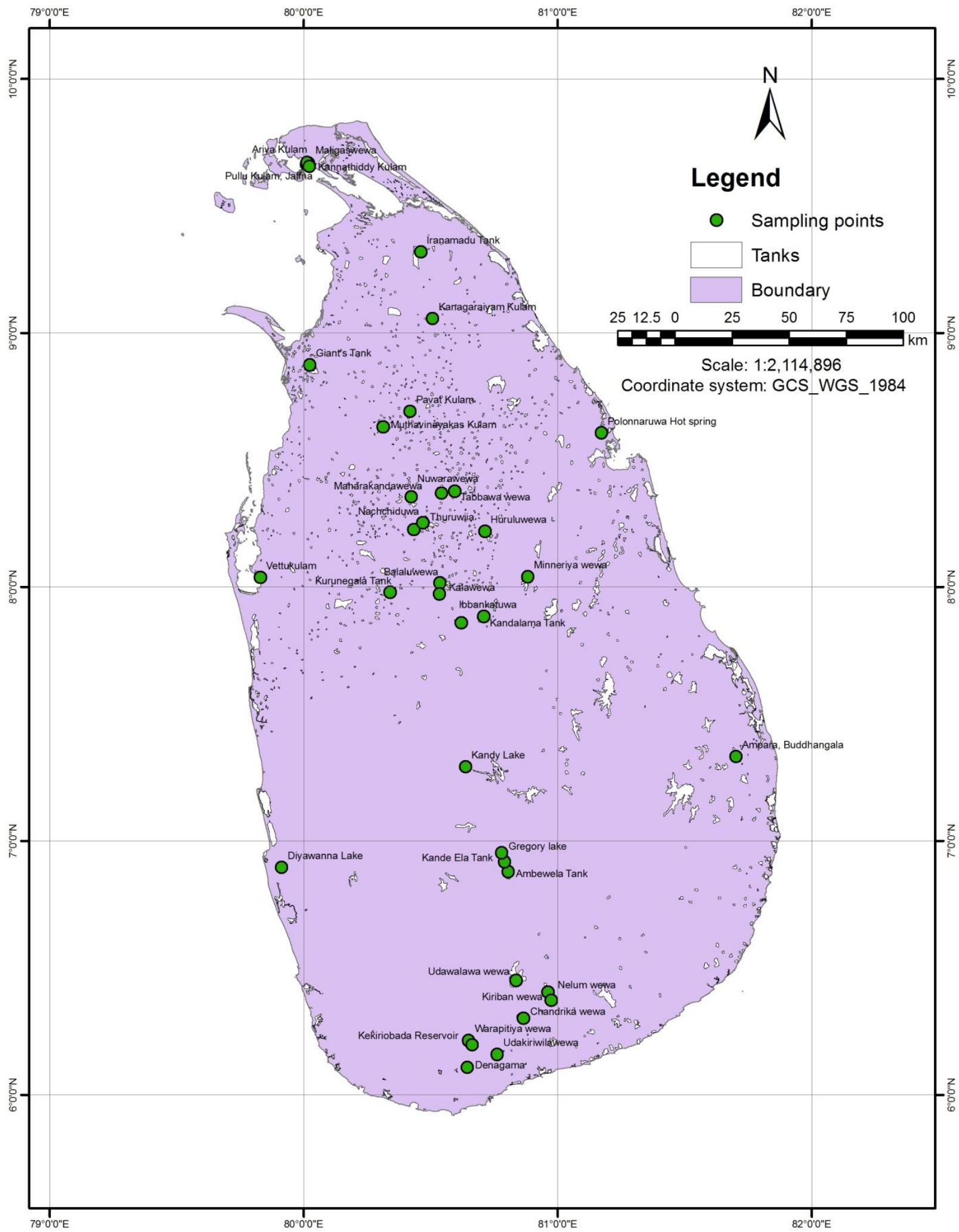

Figure 1: Sampling locations (reservoirs) in Sri Lanka. 


\section{Morphological identification}

A small aliquot of an isolated culture was observed under a Compound Microscope (Euromex, BioBlue.Lab BB. 1153-PLi) and the identification of specimens was carried out using morphological characteristics described by Desikachery (1959). The following parameters were taken into account during the identification viz., length and width of vegetative cells, morphology of the terminal cells, the presence or absence of heterocysts, akinetes and gas vesicles, the distance between heterocysts and the distance between a heterocyst and the nearest akinete and the shape of filaments and their potential aggregation into colonies.

\section{STATISTICAL ANALYSIS}

Statistical analyses were done for water temperature, $\mathrm{pH}$ and turbidity measurements using ANOVA in SAS 9.1 (SAS, 1999) and MINITAB-16.

\section{RESULTS AND DISCUSSION}

In the present study, the cyanobacterial occurrence had a strong positive correlation with abiotic properties of water i.e., water temperature, $\mathrm{pH}$ and secchi depth (Table 1). Also, the number of sampling reservoirs was found to be positively correlated with number of cyanobacteria isolated from three climatic zones (Table 1). In the present study, a total of 64 uni- algal cultures were obtained and they were distributed as 48, 10 and 6 from reservoirs in Dry, Wet and Intermediate zones, respectively. The identified strains from the Dry Zone were belonged to Oscillatoria sp., Phormidium sp., Pseudoanabaena sp., Gleocapsa sp., Planktolyngbya sp., Microcystis sp., Limnothrix sp., Microcoleus sp., Aphanotecae sp., Scynechcoccus sp., Lyngbya sp., Planktothrix sp., Chroococcidiopsis sp., Anabaena sp., Nostoc sp. and Microchaete sp. Ten strains (from 10 unialgal cultures) including Anabaena sp., Plectonema sp., Lyngbya sp., Calothrix sp., Chroococcus sp., Dermocarpa sp., Leptolyngbya sp., Oscillatoria sp., Scynechococcus sp., Microcystis sp., were isolated from reservoirs in the Wet Zone while only four species (from 6 uni-algal cultures) were isolated from the Intermediate Zone which include Oscillatoria sp., Microcystis sp., Spirulina sp. and Chrococcus sp. The frequency of isolating Oscillatoria sp. was high (10 water bodies) from the reservoirs examined, followed by Microcleus sp. and Microcystis sp. (each from 6 water bodies) (Figure 2).

According to the present study, the highest water temperature $\left(31.35 \pm 1.50^{\circ} \mathrm{C}\right), \mathrm{pH}(8.20 \pm$ $0.68)$ and Secchi depth $(75.09 \pm 26.31 \mathrm{~cm})$ were recorded in dry zone reservoirs whereas the lowest recorded in the wet zone. The abiotic properties of water samples of the three climatic zones are shown in Table 2.

Table 1: Correlation between multiple parameters in the current study.

\begin{tabular}{lrrrrrr}
\hline & $\begin{array}{r}\text { Climatic } \\
\text { Zone }\end{array}$ & $\begin{array}{c}\text { Water } \\
\text { Temp }\left({ }^{\mathbf{0}} \mathbf{C}\right)\end{array}$ & $\mathbf{p H}$ & $\begin{array}{c}\text { Secchi Depth } \\
(\mathbf{c m})\end{array}$ & Occurrence & Reservoir \\
\hline Climatic Zone & 1.000 & & & & & \\
Water Temp $\left({ }^{\circ} \mathrm{C}\right)$ & 0.953 & 1.000 & & & & \\
pH & 0.950 & 0.810 & 1.000 & & & \\
Secchi Depth $(\mathrm{cm})$ & 0.977 & 0.865 & 0.995 & 1.000 & & \\
Occurrence & 0.820 & 0.607 & 0.958 & 0.924 & 1.000 & \\
Reservoirs & 0.866 & 0.673 & 0.979 & 0.953 & 0.996 & 1.000 \\
\hline
\end{tabular}

Table 2: Abiotic properties of different reservoirs in three climatic zones of Sri Lanka.

\begin{tabular}{llll}
\hline Climatic Zone & Water Temperature $\left({ }^{0} \mathbf{C}\right)$ & pH & Secchi Depth $(\mathbf{c m})$ \\
\hline Dry Zone & $31.35 \pm 1.50^{\mathrm{c}}$ & $8.20 \pm 0.68^{\mathrm{c}}$ & $75.09 \pm 26.31^{\mathrm{c}}$ \\
Intermediate Zone & $29.12 \pm 1.82^{\mathrm{b}}$ & $7.58 \pm 0.44^{\mathrm{b}}$ & $62.60 \pm 11.97^{\mathrm{b}}$ \\
Wet Zone & $21.37 \pm 1.27^{\mathrm{a}}$ & $7.41 \pm 0.24^{\mathrm{a}}$ & $57.00 \pm 39.69^{\mathrm{a}}$ \\
\hline
\end{tabular}

Values given are the mean of 93 samples from dry zone and 9 samples from intermediate and wet zone each. Superscript letters in each column indicate significant differences $(p<0.05)$ 


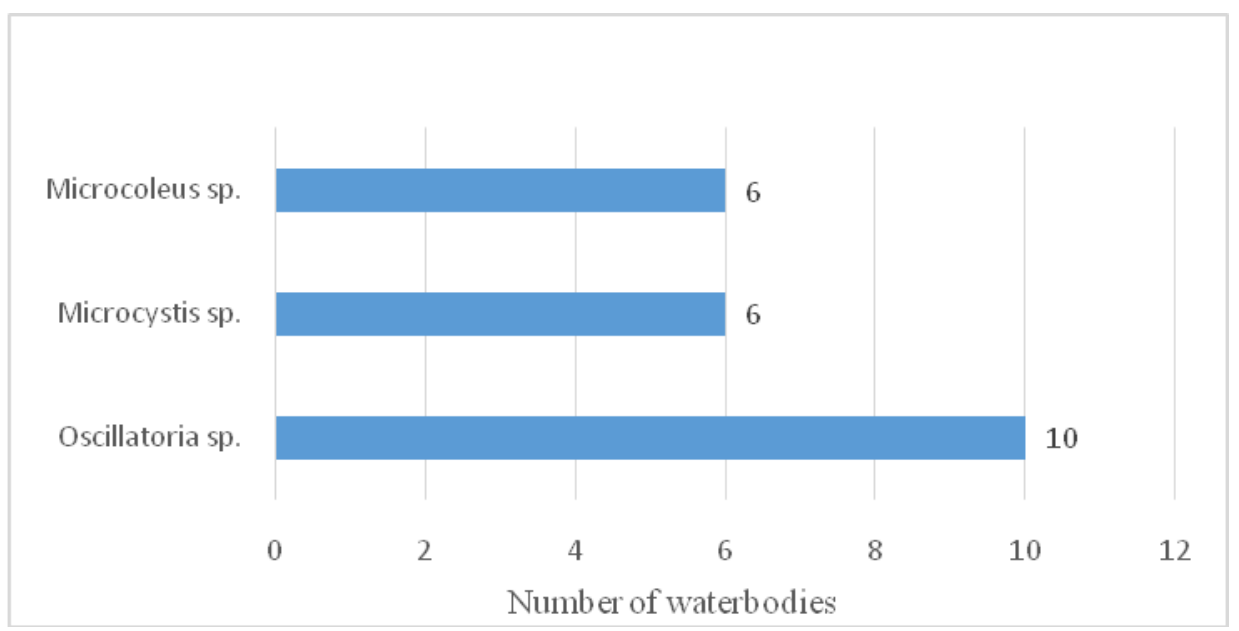

Figure 2: Frequencies of algal species recorded in reservoirs located in three climatic zones in Sri Lanka.

Table 3: Time taken to appear the growth in each media (in days).

\begin{tabular}{|c|c|c|c|c|}
\hline \multirow{2}{*}{ Climatic zone } & \multicolumn{2}{|c|}{ Media with original water } & \multicolumn{2}{|c|}{ Media with distilled water } \\
\hline & BG 11 & $\mathrm{GO}$ & BG 11 & $\mathrm{GO}$ \\
\hline Dry zone & $8.33 \pm 1.53$ & $12.5 \pm 3.54^{* *}$ & $14.00 \pm 40$ & $20.00 \pm 1.41^{* *}$ \\
\hline Intermediate zone & $8.33 \pm 3.06$ & $8.00 \pm 00^{*}$ & $13.33 \pm 3.79$ & $13.00 \pm 00^{*}$ \\
\hline Wet zone & $12.67 \pm 2.52$ & $18.00 \pm 1.41^{* *}$ & $19.67 \pm 3.06$ & $20.50 \pm 2.12^{* *}$ \\
\hline
\end{tabular}

\section{Growth of cyanobacteria}

Generally, the appearance of cyanobacterial growth took place after about 2 to 3 weeks, mainly depend on the climatic zone and other abiotic parameters of the reservoirs (Table 3). However, the growth in agar supplemented media takes even longer than that of liquid media. According to the results, the samples prepared in water taken from respective reservoirs grew faster than samples prepared in distilled water, regardless of the climatic zone (Table 3). It is most likely that the water from respective reservoirs provided more favorable conditions for the survival and the growth of opportunistic (fast-growing) taxa those having superior survival skills. Also, the cyanobacterial cells can get an osmotic shock once they transfer into distilled water in addition to the changes of other physical and chemical characteristics including temperature, $\mathrm{pH}$, and nutrients.

The results also suggested that cyanobacterial taxa grew faster in BG11 medium compared to the GO medium. In the medium of
BG-11, the growth appeared in all samples (Table 3) whereas in the $\mathrm{N}$-free $\mathrm{GO}$ medium the isolates were predominantly heterocystous.

\section{Composition of Cyanobacterial taxa}

About 40 species of cyanobacteria belonging to 24 genera have been reported so far from reservoirs in Sri Lanka (Silva and Wijeyaratne, 1999). Of these, except for Microcystis aeruginosa, other species are either rare or occur only in small numbers (Silva and Wijeyaratne, 1999). However, more recent reports, encompassing several reservoirs, on the occurrence of freshwater cyanobacteria give evidence of Cylindrospermopsis as dominant taxa in addition to Microcystis (Perera et al., 2011). However, in the present study Cylindrospermopsis was not observed in any reservoirs studied. This is perhaps due to the inability of these two media that used in the present study to support its growth or else it could be due to misidentification it as Planktolyngbya as a result of their close resemblance under in vitro conditions. 
Traditionally, the classification of cyanobacteria has been based on morphological characters such as trichome width, cell size, division planes, shape and arrangement, pigmentation and the presence of characters such as gas vacuoles and a sheath (Baker, 1991, 1992; Bourrelly, 1970; Komarek and Anagnostidis, 1986, 1989). However, a considerable expertise is required to identify species with the help of these characters and the subjective judgment by operators can lead to errors resulting or incorrect identification of isolates. Komarek and Anagnostidis (1989) estimated that more than $50 \%$ of the strains in culture collections are misidentified. Moreover, some diagnostic characteristics, such as gas vacuoles and/or akinetes, can show variations with different environmental or growth conditions and even be lost during cultivation (Rudi et al., 1997; Lyra et al., 2001). Such limitations of using phenotypic characters in identification of cyanobacterial taxa have highlighted the importance of using more reliable method/s. The molecular approaches in cyanobacterial taxonomy including DNA base composition (Kaneko et al., 1996, 2001), DNA hybridizations (Kondo et al., 2000), gene sequencing (Nubel et al., 1997) and PCR fingerprinting (Rasmussen and Svenning, 1998; Versalovic et al., 1991) has been highlighted as a result. Furthermore, cyanobacterial-specific methods not requiring axenic cultures are of utmost importance since such cultures are difficult to obtain (Choi et al., 2008). Some of the representative isolates from the present study are presented in figure 3 .

\section{CONCLUSIONS}

Though a number of studies were carried to evaluate the occurrence of cyanobacteria in fresh water bodies in Sri Lanka, the present study provided baseline information on culturable cyanobacteria from freshwater bodies. In the present study, a total 64 culturable cyanobacteria were isolated. The study revealed that occurrence of cyanobacteria has a positive relationship with water temperature, $\mathrm{pH}$ and turbidity. Also, water from respective reservoirs provides favorable conditions for cyanobacterial growth rather than chemical media alone. Future studies can be carried out with the help of molecular identification of the isolates.

\section{ACKNOWLEDGEMENTS}

The authors would like to thank Mr. N.P. Athukorale, Ms. R.K.C. Karunaratne, Ms. R.S.M. Perera and Ms. I. Tumpela (Senior Staff Technical Officer, NIFS, Sri Lanka) for their support during sample collection and analysis. Authors are grateful to EFE \& GB nets, UK for providing sample collection nets.

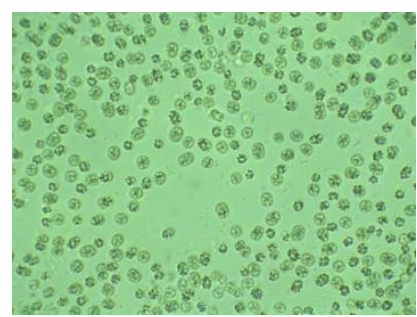

A

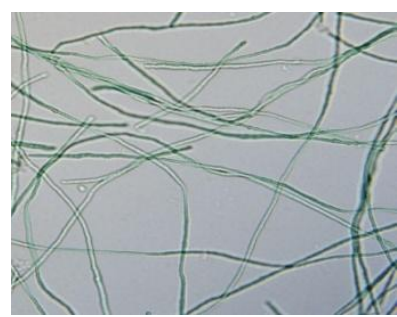

B

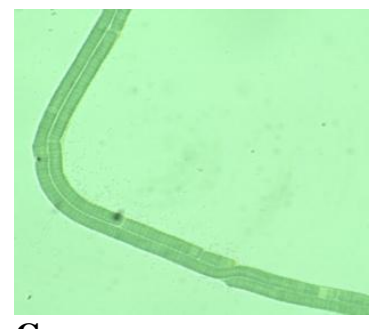

C

Figure 3: A: Microcystis sp., B: Leptolyngbya sp. and C: Oscillatoria sp. recorded in the study. 


\section{REFERENCES}

Abeywickrama, B., (1979) The genera of the fresh water algae of Sri Lanka, Part 1-UNESCO Man and the biosphere national committee for Sri Lanka. Special Publication 6.

Abou-Shanab, A. R., Hwang, J. H., Cho, Y., Min, B., and Jeon, B. H., (2011). Characterization of microalgal species isolated from fresh water bodies as a potential source for biodiesel production. Applied Energy 88(10): 3300-3306.

Baker, P., (1991). Identification of Common Noxious Cyanobacteria Part I - Nostocales: Urban Water Research Association of Australia. Research Report: 29.

Baker, P., (1992). Identification of Common Noxious Cyanobacteria Part II - Chroococales Oscillatoriales: Urban Water Research Association of Australia. Research Report: 46.

Bourrelly, P., (1970). Les Algues d'Eau Douce: Les Algues Bleus et Rouges, Les Eugléniens, Peridiniens, et Cryptomonadines. Paris: $N$. Boube'e \& Cie.

Cepoi, L., Rudi, L., Chiriac, T., Codreanu, S., and Valuţa, A., (2016). Biological Methods of Wastewater Treatment Cyanobacteria for Bioremediation of Wastewaters. Springer, 45-60.

Choi, G. G., Bae, M. S., Ahn, C. Y., and Oh, H. M., (2008). Induction of axenic culture of Arthrospira (Spirulina) platensis based on antibiotic sensitivity of contaminating bacteria. Biotechnol Lett 30: 8792.

Crow, W. B., (1923). The taxonomy and variation of the genus Microcystis in Ceylon. New Phytologist 22(2): 59-68.

Silva, P., (1992). Some aspects of the limnology and the fishery of Kotmale and Randenigala reservoirs in Sri Lanka. Sri Lankan Journal of Agricultural Sciences (Sri Lanka).

Desikachary, T., (1959). Cyanophyta. Indian Council of Agricultural Research. New Delhi.

Foged, N., Foged, N., Botaniste, D., Foged, N., \& Botanist, D., (1976). Freshwater diatoms in Sri Lanka (Ceylon): J. Cramer.

Holsinger, E., (1955). The plankton algae of three Ceylon lakes. Hydrobiologia 7(1): 8-24.

Hossain, M. F., Ratnayake, R., Meerajini, K., and Kumara, K. L. W., (2016). Antioxidant properties in some selected cyanobacteria isolated from fresh water bodies of Sri Lanka. Food Science \& Nutrition.

Idroos, S., and Manage, P., (2015). Toxin Producing Cyanobacteria in Labugama, Kalatuwawa Drinking Water Reservoirs. Paper presented at the Proceedings of International Forestry and Environment Symposium.

Jayatissa, L., Silva, E., McElhiney, J., and Lawton, L., (2006). Occurrence of toxigenic cyanobacterial blooms in freshwaters of Sri Lanka. Systematic and Applied Microbiology 29(2): 156-164.
Jayawardana B. P. A., J. M. J. C., Jayalath, J. P. D., Padmasiri, and Kulasooriya S. A., (1998) Occurrence of potential toxin producing cyanobacteria in reservoirs of Sri Lanka. In: Symposium on Cyanobacterial Toxins in Water. Postgraduate Institute of Science, University of Peradeniya: 7.

Kaneko, T., Sato, S., Kotani, H., Tanaka, A., Asamizu, E., Nakamura, Y., Miyajima, N., Hirosawa, M., Sugiura, M., and other authors, (1996). Sequence analysis of the genome of the unicellular cyanobacterium Synechocystis sp. strain PCC 6803. II. Sequence determination of the entire genome and assignment of potential proteincoding regions. DNA Res 3: 109-136.

Kaneko, T., Nakamura, Y., Wolk, C. P., Kuritz, T., Sasamoto, S., Watanabe, A., Iriguchi, A., Ishikama, K., Kawashima, K., and other authors, (2001). Complete genomic sequence of the filamentous nitrogen-fixing cyanobacterium Anabaena sp. strain PCC 7120. DNA Res 8: 205213.

Kulasooriya, S. A., (2012). Cyanobacteria: pioneers of planet earth. Ceylon Journal of Science (Biological Sciences) 40(2).

Kulasooriya, S. A., (1998) Freshwater cyanobacteria and their relevance to water supply in Sri Lanka. In: Symposium on Cyanobacterial toxins in water. Postgraduate Institute of Science, University of Peradeniya: 8.

Kulasooriya, S. A. and Silva R. S. Y., (1981). Multivariate interpretation of the distribution of nitrogen fixing blue-green algae in rice fields of Central Sri Lanla. Annals of Botany, (Lond) 47: 3 -51 .

Komarek, J., and Anagnostidis, K., (1986). Modern approach to the classification system of Cyanophytes.2. Chroococcales. Algol Stud 43: 157-226.

Koma'rek, J., and Anagnostidis, K., (1989). Modern approach to the classification system of Cyanophytes. 4. Nostocales. Algol Stud 56: 247345.

Kondo, R., Yoshida, T., Yusi, Y., and Hiroishi, S., (2000). DNA-DNA reassociation among a bloomforming cyanobacterial genus, Microcystis. Int $J$ Syst Evol Microbiol 50: 767-770.

Lyra, C., Suomalainen, S., Gugger, M., Vezie, C., Sundman, P., Paulin, L., and Sivonen, K., (2001). Molecular characterization of planktic cyanobacteria of Anabaena, Aphanizomenon, Microcystis and Planktothrix genera. Int J Syst Evol Microbiol 51: 513-526.

Perera, M.B.U. Yatigammana, S.K., and Kulasooriya, S. A., (2012). Prevalence of Toxigenic Cyanobacteria in Different Climatic Zones of Sri Lanka. Symposium Proceedings. International Symposium on Water Quality and Human Health: Challenges Ahead, PGIS, Peradeniya, Sri Lanka. 
Perera, M.B.U., and Yatigammana, S. K.,(2014). Distribution and Composition of Cyanobacteria in Sri Lankan Reservoirs. Symposium Proceedings, Third International Symposium on Water Quality and Human Health: Challenges Ahead, PGIS, Peradeniya, Sri Lanka:14.

Magana-Arachchi, D. N., and Wanigatunge, R., (2013). First report of genus Chroococcidiopsis (cyanobacteria) from Sri Lanka: a potential threat to human health. Journal of the National Science Foundation of Sri Lanka 41(1): 65-68.

Magana-Arachchi, D. N., Wanigatunge, R., and Liyanage, M., (2011). Molecular characterization of cyanobacterial diversity in Lake Gregory, Sri Lanka. Chinese Journal of Oceanology and Limnology 29(4): 898-904.

Magana-Arachchi, D. N, Wanigatunge, R., and Jeyanandarajah, P., (2009). Setting up a polymerase chain reaction assay for the detection of toxic cyanobacteria. Journal of the National Science Foundation of Sri Lanka 36(3).

Nubel, U., Garcial-Pichel, F., and Muyzer, G., (1997). PCR primers to amplify 16S rRNA genes from Cyanobacteria. Appl Environ Microbiol 63: 3327 3332.

Pandey, V., (2015). Cyanobacterial natural products as antimicrobial agents. Int. J. Curr. Microbiol. App. Sci 4(1): 310-317.

Pathiratne, A., Pathiratne, K., and Seram, P., (2010). Assessment of biological effects of pollutants in a hyper eutrophic tropical water body, Lake Beira, Sri Lanka using multiple biomarker responses of resident fish, Nile tilapia (Oreochromis niloticus). Ecotoxicology 19(6): 1019-1026.

Perera, B., Yatigammana, S., Kulasooriya, A., (2011). Diversity of plankton in some selected reservoirs of Sri Lanka. International Symposium on Sustainable Use of Water: Challenges Ahead PGIS: 36-37.

Pereira, H., Barreira, L., Mozes, A., Florindo, C., Polo, C., Duarte, C. V., Varela, J., (2011). Microplate-based high throughput screening procedure for the isolation of lipid-rich marine microalgae. Biotechnology for biofuels 4(1): 1-12.

Pulz, O., and Gross, W. (2004). Valuable products from biotechnology of microalgae. Applied Microbiology and Biotechnology, 65(6): 635-648.

Rasmussen, U., and Svenning, M. M., (1998). Fingerprinting of cyanobacteria based on PCR with primers derived from short and long tandemly repeated repetitive sequences. Appl Environ Microbiol 64: 265-272.

Rippka, R., Waterbury, J. B., \& Stanier, R. Y. (1981). Isolation and purification of cyanobacteria: some general principles The prokaryotes Springer: 212220.
Rippka, R., Deruelles, J., Waterbury, J. B., Herdman, M., and Stanier, R. Y., (1979). Generic assignments, strain histories and properties of pure cultures of cyanobacteria. Journal of General Microbiology 111(1): 1-61.

Rott, E., and Lenzenweger, R. (1994). Some rare and interesting plankton algae from Sri Lankan reservoirs. Biologia. Ser. A.(Slovakia).

Rudi, K., Skulberg, O. M., Larsen, F., and Jakobsen, K. S., (1997). Strain characterization and classification of oxyphotobacteria in clone cultures on the basis of $16 \mathrm{~S}$ rRNA sequences from the variable regions V6, V7, and V8. Appl Environ Microbiol 63: 2593-2599.

Shatheesh K. M., (2013). Biotechnological potentials of indigenous cyanobacteria in crop improvement and bioremediation.

Silva, E., and Wijeyaratne, M., (1999). The occurrence of cyanobacteria in the reservoir of the Mahaweli River Basin in Sri Lanka. Sri Lanka J. Aquat. Sci 4: 51-60.

Stanier, R., Kunisawa, R., Mandel, M., and CohenBazire, G., (1971). Purification and properties of unicellular blue-green algae (order Chroococcales). Bacteriological Reviews 35(2): 171.

Tobschall, H., and Dissanayake, C., (1986). Precious metals in cyanobacterial mats of Manner Lagoon, Sri Lanka. Paper presented at the Abstracts, The 12th International Sedimentological Congress, August, Canberra, Australia.

Versalovic, J., Koeuth, T., and Lupski, J. R., (1991). Distribution of repetitive DNA sequences in eubacteria and application to fingerprinting of bacterial genomes. Nucleic Acids Res 19: 68236831.

Vincze, T., Posfai, J. and Roberts, R. J., (2003). NEBcutter: a program to cleave DNA with restriction enzymes. Nucleic Acids Res 31: 36883691.

Waterbury, J. B., (2006). The cyanobacteria-isolation, purification and identification The prokaryotes Springer: 1053-1073.

West, W., and West, G. S., (1902). III. A Contribution to the Freshwater Algæ of Ceylon. Transactions of the Linnean Society of London. 2nd Series: Botany 6(3): 123-215.

Weerakoon, A. A., Jayawardana, B. P. A., Padmasiri, J. P. D., and Kulasooriya, S. A., (1998) Comparison of algal populations of Tisawewa and Basawakulama tanks in Anuradhapura. In: Symposium on Cyanobacterial Toxins in Water. Postgraduate Institute of Science, University of Peradeniya: 11.

Whitton, B. A., (2000). Soils and rice-fields The ecology of cyanobacteria Springer: 233-255. 